\title{
Behaviour of industrial machinery foundation on pre stressed geogrid-reinforced embankment over soft soil under static load
}

\author{
Masih Allahbakhshi ${ }^{1,}$, Habib Sadeghi ${ }^{2}$ \\ ${ }^{1}$ Department of Civil Engineering, Mazandaran University of technology, Babol, Iran \\ ${ }^{2}$ Department of Chemical Engineering, Isfahan University, Isfahan, Iran
}

Email address:

masih2768@gmail.com (M. Allahbakhshi)

\section{To cite this article:}

Masih Allahbakhshi, Habib Sadeghi. Behaviour of Industrial Machinery Foundation on Pre Stressed Geo Grid-Reinforced Embankment over Soft Soil under Static Load. Science Journal of Energy Engineering. Vol. 2, No. 6, 2014, pp. 65-73.

doi: 10.11648/j.sjee.20140206.11

\begin{abstract}
Results of parametric study to investigate the applicability of finite element method for analyzing industrial machinery foundation on pre stressed-reinforced embankment over soft soil are investigated in this paper. Model tests were carried out using model footing of $1 \mathrm{~m}$ in diameter and geogrids. Particular emphasis is paid on the reinforcement configurations including number of layers, spacing, layer length and depth to ground surface on the behavior of industrial machinery foundation on reinforced silty sand embankment on peat and soft clay under static load is determined. A series of finite element analyses were performed on a slope using two-dimensional plane strain model using the computer code Plaxis. Soil was represented by non-linear hardening soil model, which is an elasto-plastic hyperbolic stress-strain model while reinforcement was represented by elastic elements. Test results indicate that the inclusion of geogrid layers in sand not only significantly improves the footing performance but also leads to great reduction in the depth of reinforced sand layer required to achieve the allowable settlement. However, the efficiency of the sand-geogrid system increases with increasing number of geogrid layers and layer length. Based on the theoretical results. In this paper we can see the effect of pre stressed geotextile is more than that unreinforced and reinforced (without pre stress) embankment.
\end{abstract}

Keywords: Bearing Capacity, Industrial Machinery Foundation, Pre stressed - Reinforced Embankment, Soft Soil, Finite Element Analyses

\section{Introduction}

Soil can resist pressure and shear forces very well, but it is not able to tolerate tensile forces. Reinforced soil is composite material that contains components that can easily stand tensile forces. Nowadays reinforcing materials is widely used to overcome technical problems. Reinforced soil is used in stabilizing embankment (slope), fill dams, retaining walls, foundation and in-situ slope for increasing the shear resistance of soil layer in different earth structures. The subject of reinforcing soil beneath footings has gained considerable attention in the past few years (e.g. Dash et al., 2003; Boushehrian and Hataf, 2003; Ghosh et al., 2005; Bera et al., 2005; Patra et al., 2005, 2006).This paper is interested in the many situations where footings are constructed on/or adjacent to soft clay sloping surfaces under static load such as industrial machinery footings on sloping embankments. In this case, two major problems arise; the low bearing capacity of soft clay and the potential failure of the slope itself. Therefore, over some years, the subject of stabilizing earth slope has become one of the most interesting areas for scientific research and several techniques have been suggested to improve the stability of earth slope and hence improve the bearing capacity. Typical examples include modifying the slope surface geometry, chemical grouting, using soil reinforcement, or installing continuous or discrete retaining structures such as walls or piles. Geosynthetics recognized as synthetic materials are used in soil. The specific families of Geosynthetics are the following: Geotextiles, Geogrids, Geomembranes and Geocomposites. When synthetic fibers are made into a flexible, porous fabric by standard weaving machinery or are matted together in woven and nonwoven manner, the product known as "Geotextile". 
Geogrids are plastics formed into a very open netlike configuration. Geotextiles and Geogrids are used usually as reinforcing material for soil improvement. These reinforcing materials are not susceptible to corrosion, have relatively low stiffness and flexible enough to tolerate large deformation. These factors make them to be superior to steel reinforcing materials in soils. As use of geotextile in reinforcing embankment is growing. Several case studies described the successful use of geogrids to reinforce a weak subgrade such as variable soft clay (Tsukada et al., 1993; Khing et al. (1993); British Rail Research, 1998; Omar et al. (1993); Dashet al., 2003; Yetimoglu et al., 1994; Sitharam and Sireesh (2004).

Tsukada et al. (1993) investigated the use of geogrids for roadway foundation and reported that settlement response and pressure distributions were directly related to the thickness and configuration of the geogrid-reinforced foundation. Khing et al. (1993) conducted model tests on a strip footing supported by a sand layer reinforced with layers of geogrid. The test results show that the maximum benefit of geogrid reinforcement in increasing the bearing capacity was obtained when the ratio of the depth of the first reinforcing layer to the foundation width was less than unity. British Rail Research (1998) has demonstrated that geogrid inserted in the ballast where tracks lie over soft ground can help extend maintenance intervals. Omar et al. (1993) presented the results of the laboratory model tests for strip and square foundations supported by sand reinforced with geogrid layers. The test results demonstrate that for the development of maximum bearing capacity, the depth of reinforcement is about $2 \mathrm{~B}$ for strip foundation and 1.4B for square foundation, where $B$ is the width of the footing. The maximum depth of placement of the first layer of geogrid should be less than about B to take advantage of reinforcement. Dash et al. (2003) performed model tests in the laboratory to study the response of reinforcing granular fill overlying soft clay beds and showed that substantial improvements in the load carrying capacity and reduction in surface heaving of the foundation bed were obtained. Yetimoglu et al. (1994) conducted laboratory model tests to investigate the bearing capacity of rectangular footings on geogrid-reinforced sand. For a single layer of geogrid reinforcement, the optimal placement depth was 0.3 times the footing width. Sitharam and Sireesh (2004) conducted laboratory model tests to determine the bearing capacity of an embedded circular footing supported by sand bed reinforced with multiple layers of geogrids. The test results demonstrate that the ultimate bearing pressure increases with embedment depth ratio of the foundation.

\section{Prototype Study}

\subsection{Finite Element Analysis}

A series of two-dimensional finite element analyses (FEA) on a prototype footing-slope system was performed in order to understand the deformations trends within the soil mass. The analysis was performed using the finite element program Plaxis software package (professional version 8, Bringkgreve and Vermeer, 1998). Plaxis is capable of handling a wide range of geotechnical problems such as deep excavations, tunnels, and earth structures such as retaining walls and slopes. The software allows the automatic generation of six or fifteen node triangle plane strain elements for the soil, and three or five node beam elements for the footing while three or five node elastic elements were used for the geotextile elements. Initial step for analyzing the models to create the geometry of the model. The geometry characteristics such as embankment height, slope and crest width. The other geometry which should be defined is under laying soil profile such as thickness of the soft layer. The second step is to provide the material properties of the embankment and the under laying soil. For present investigation the main model with $4 \mathrm{~m}$ height, $8 \mathrm{~m}$ crest width, $1: 3(\mathrm{~V}: \mathrm{H})$ slope and is placed on a peat layer of $3 \mathrm{~m}$ thickness and soft clayey layer of $3 \mathrm{~m}$ thickness and the vibrating source is an industrial machinery founded on a $0.2 \mathrm{~m}$ thick concrete footing of $1 \mathrm{~m}$ in diameter. In addition to the weight of the footing, the weight of the industrial machinery is assumed $5 \mathrm{kN} / \mathrm{m}^{2}$, modelled as a uniformly distributed load and special boundary conditions have to be defined to account for the fact that in reality the soil is a semi-infinite medium.

\subsection{Finite Element Modeling}

The non-linear behavior of sand was modeled using hardening soil model, which is an elasto-plastic hyperbolic stress-strain model, formulated in the framework of friction hardening plasticity. The foundation was treated as elastic beam elements based on Mindlin's beam theory with significant flexural rigidity (EI) and normal stiffness (EA). A basic feature of the hyperbolic model is the stress dependency of soil stiffness. The interaction between the geogrid and soil is modeled at both sides by means of interface elements, which allow for the specification of a reduced wall friction compared to the friction of the soil. The limiting state of stress are described by means of the secant Young's modulus ( $\left.\mathrm{E}_{50}^{\mathrm{ref}}\right)$, tangent stiffness modulus for primary compression ( $\left.E_{\text {oed }}^{\text {ref }}\right)$, Poisson's ratio $(v)$, effective cohesion (c), angle of internal friction $(\Phi)$, angle of dilatancy $(\psi)$, failure ratio $\left(\mathrm{R}_{\mathrm{f}}\right)$ and interface reduction factor $\left(\mathrm{R}_{\text {int }}\right)$. The modeled boundary conditions were assumed such that the vertical boundaries are free vertically and constrained horizontally while the bottom horizontal boundary is fully fixed. The software allows the automatic generation of six node triangle plane strain elements for the soil, and three node beam elements for the footing and the geogrid. The number of element used in reinforced tests are 250 element while in unreinforced tests the number is 160 . The analyzed model slope geometry, generated mesh, and the boundary conditions are shown in Fig. 1. An internal angle of friction and secant Young's modulus $\left(E_{50}^{\text {ref }}\right)$ representing dense sand conditions derived from a series of drained tri axial compression tests were used for the sand. A value of 10 $\mathrm{kN} / \mathrm{m}^{2}$ to the undrained cohesion (c) for the peat and 25 $\mathrm{kN} / \mathrm{m}^{2}$ for the soft clay derived from undrained tri axial compression tests was used. Then hyperbolic parameters for the sand, peat and clay were taken from database provided by 
the software manual as shown in Table 1.

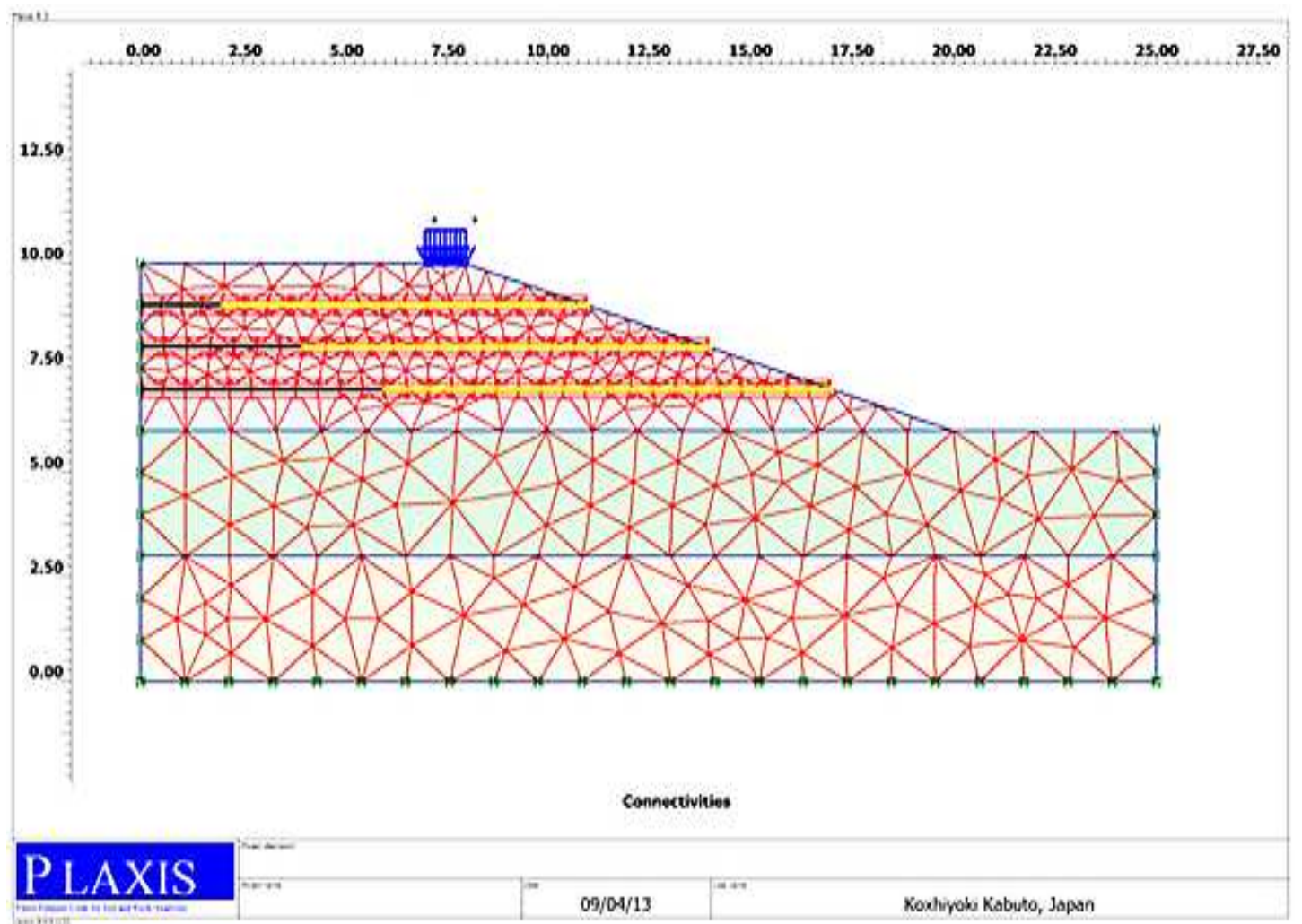

Fig. 1. Prototype slope geometry, generated mesh, and boundary conditions.

Table 1. Hardening soil-footing model parameters used in the finite element analysis.

\begin{tabular}{|c|c|c|c|c|c|}
\hline Parameter & sand & peat & soft clay & Footing & Geogrid \\
\hline Primary loading stiffness $\left(E_{50}^{r e f}\right)\left(\mathrm{kN} / \mathrm{m}^{2}\right)$ & 45000 & 10000 & 15000 & - & - \\
\hline Cohesion $(\mathrm{c})\left(\mathrm{kN} / \mathrm{m}^{2}\right)$ & 0.00 & 10 & 25 & - & - \\
\hline Friction angle $(\phi)$ & 35 & 5 & 2 & - & - \\
\hline Dilatancy angle $(\psi)$ & 10 & 0.00 & 0.00 & - & - \\
\hline Soil unit weight $(\gamma)\left(\mathrm{kN} / \mathrm{m}^{3}\right)$ & 20 & 13.5 & 18 & - & - \\
\hline Poisson's ratio $(v)$ & 0.30 & 0.35 & 0.35 & - & - \\
\hline Failure ratio $\left(\mathrm{R}_{\mathrm{f}}\right)$ & 0.90 & 0.90 & 0.90 & - & - \\
\hline Interface reduction factor $\left(\mathrm{R}_{\text {int }}\right)$ & 0.80 & 0.50 & 0.30 & - & - \\
\hline EA of the footing $(\mathrm{kN} / \mathrm{m})$ & - & - & - & 7600000 & - \\
\hline EI of the footing $\left(\mathrm{kNm}^{2} / \mathrm{m}\right)$ & - & - & - & 24000 & - \\
\hline EA of the geogrid $(\mathrm{kN} / \mathrm{m})$ & - & - & - & & 2500 \\
\hline
\end{tabular}

\section{Results and Discussion}

A total of 54 model tests were carried out on model plane strain footing supported on sand pads overlying peat and soft clay ground slope. The effect of geogrid parameters on the ultimate load and displacement were obtained and discussed. An additional numerical study on the effect of reinforcing the sand pad on the behavior of a model footing was carried out using the finite element model.

\subsection{Bearing Capacity Behavior}

The BCI of the footing on the reinforced sand is represented using a non-dimensional factor, called BCI factor. This factor is defined as the ratio of the footing ultimate pressure with the slope reinforced ( $q_{u}$ reinforced $)$ to the footing ultimate pressure in tests without slope reinforcement $\left(\mathrm{q}_{\mathrm{u}}\right)$. The footing settlement ( $S$ ) is also expressed in nondimensional form in terms of the footing width (B) as the ratio $(\mathrm{S} / \mathrm{B}, \%)$. The ultimate bearing capacities for the model footing when located on non-reinforced and reinforced sand layer obtained from the FEA are 35 and $50 \mathrm{kPa}$ respectively is determined from the load-displacement curve. The measured and calculated ultimate loads for footing supported on both reinforced and non-reinforced slopes for the different studied parameters are given in Tables 2-4. These results are discussed in the following sections.

Table 2. Results of footings located near to reinforced slopes.

\begin{tabular}{lllllllll}
\hline Test results & $\mathbf{x} / \mathbf{B}$ & & & & & & & \\
\hline & 0 & 0.5 & 1 & 1.5 & 2 & 2.5 & 3 & 3.5 \\
$\mathrm{q}(\mathrm{kPa})$ FEA & 35 & 37 & 40 & 43 & 45 & 47 & 50 & 50 \\
\hline
\end{tabular}


Table 3. Results of footings located near to reinforced slopes.

\begin{tabular}{lllllllll}
\hline Test results & L/B & & & & & & & \\
\hline & 0 & 3 & 5 & 7 & 9 & 11 & 13 & 15 \\
$\mathrm{q}(\mathrm{kPa})$ FEA & 35 & 37 & 39 & 41 & 43 & 44 & 45 & 46 \\
\hline
\end{tabular}

Table 4. Results of footings located near to reinforced slopes.

\begin{tabular}{lllllllll}
\hline Test results & L/B & & & & & & & \\
\hline & 0 & 3 & 5 & 7 & 9 & 11 & 13 & 15 \\
$\mathrm{q}(\mathrm{kPa})$ FEA & 35 & 37 & 39 & 41 & 43 & 44 & 45 & 46 \\
\hline
\end{tabular}

Table 5. Results of footings located at different locations.

\begin{tabular}{|c|c|c|c|c|c|c|c|c|c|c|c|c|}
\hline \multirow{3}{*}{ Test results } & \multicolumn{6}{|c|}{ Non-reinforced } & \multicolumn{6}{|c|}{ Reinforced } \\
\hline & $\mathrm{b} / \mathrm{B}$ & & & & & & $\mathrm{b} / \mathrm{B}$ & & & & & \\
\hline & 0 & 1 & 2 & 3 & 4 & 5 & 0 & 1 & 2 & 3 & 4 & 5 \\
\hline $\mathrm{q}(\mathrm{kPa})$ FEA & 35 & 45 & 50 & 85 & 95 & 95 & 78 & 90 & 94 & 157 & 174 & 176 \\
\hline
\end{tabular}

\subsubsection{Effect of Number of Geogrid Layers}

A series of studies were carried out in order to study the effect of varying the number of geogrid layers on the Footing- slope performance. In this series, geogrid length, location, and spacing, was kept constant but the number of geogrid layers was varied. To assess the effect of presence of number of geogrid layers, initially embankment is modeled without geogrid. In second step, one layer of geogrid is introduced at level of $1 \mathrm{~m}$ below the foundation. For third step of analyses, two layers of geogrid are considered at level of 1 mand $2 \mathrm{~m}$ below the foundation respectively. For last step of analyses, three layers of geogrid are considered and they are placed one between the embankment base and the soft layer and remaining two others in the body of embankment at level of $1 \mathrm{~m}, 2 \mathrm{~m}$ and $3 \mathrm{~m}$ below the foundation respectively. Typical variations of $\mathrm{q}$ obtained from numerical analysis against settlement ratios (S/B) for a footing located at the slope crest are shown in Figs. 2. For the same displacement ratio, the figure demonstrates that the inclusion of geogrid layers resulted in an increase in the load capacity of the model footing. Also, for the same footing load, the settlement ratio decrease significantly with increasing the number of geogrid layers. This increase in footing ultimate load can be attributed to reinforcement mechanism which derived from the passive earth resistance, interlocking in front of the transverse members, and adhesion between the longitudinal/transverse geogrid members and the sand. The mobilized passive earth resistance of soil column confined in the geogrid apertures along with the interlocking limit the spreading of slope and lateral deformations of sand particles. The mobilized tension in the reinforcement enables the geogrid to resist the imposed horizontal shear stresses built up in the soil mass beneath the loaded area and transfer them to adjacent stable layers of soils leading to a wider and deeper failure zone. Therefore, sand pad-geogrid interaction not only result in increasing the bearing capacity due to developed longer failure surface but also results in widening the contact area between sand and soft clay. As a result, the developed acting net stress due to footing load decreased leading to decreasing the consolidation settlement of soft clay. Fig. 3 presents comparisons of the variations of the calculated and measured BCI for a footing located at the slope crest for varying values of $\mathrm{N}$.

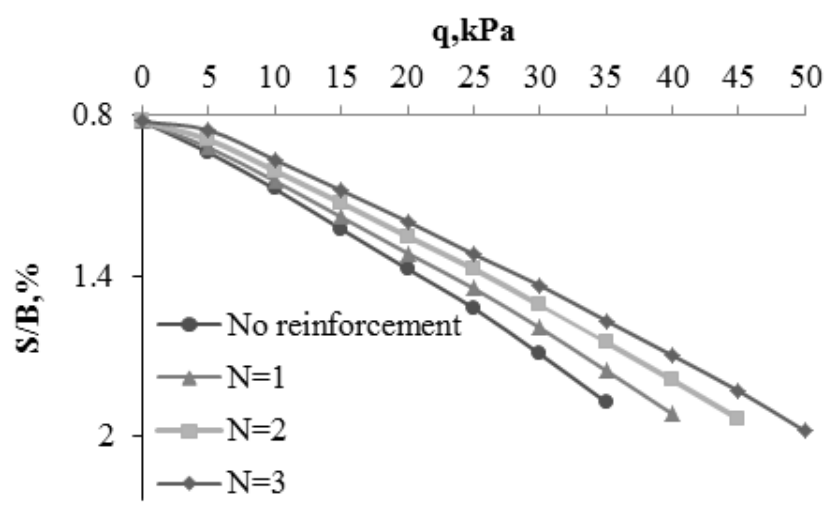

Fig. 2. Variations of $q$ with $S / B$ for prototype slope for different $N$.

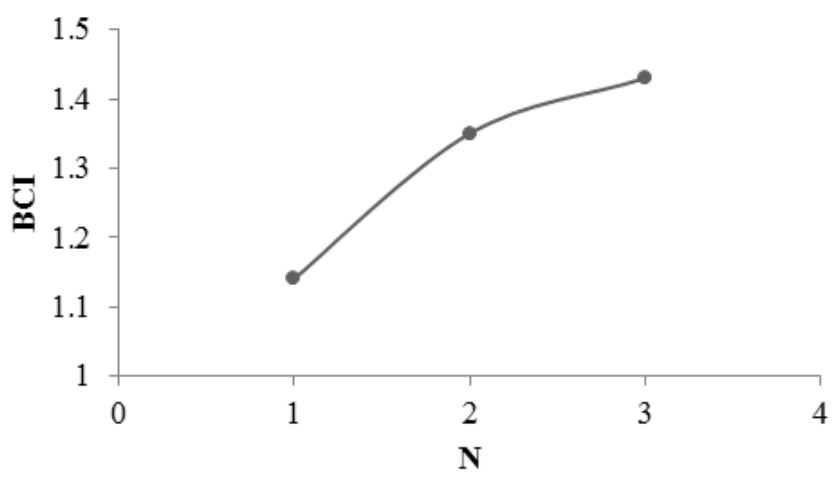

Fig. 3. Variations of BCI with number of geogrid layer, $N$.

\subsubsection{Effect of Geogrid Layer Length}

The effect of length of the geogrid layer L/B is studied using only one layer of geogrid placed in dense sand at $2 \mathrm{~m}$ beneath of the footing. In order to determine how far to extend the geogrid layers into the soil mass to provide an adequate anchorage length for each geogrid layer, seven tests were carried out to study the effect of varying the layer length on the footing behavior. Fig.4. shows the variations of BCI with the geogrid length for model slope-footing system. The BCI increases with increasing geogrid length. This behavior illustrates that sufficient anchorage lengths must be provided to maximize the reinforcing effect through full mobilization of pullout capacity of the reinforcements. With short layers of geogrid, the anchorage length of geogrid in sand is insufficient and the mobilized lateral resistance by passive resistance, interlocking and friction in the stable mass of soil is less than the transferred horizontal shear stresses 
and the geogrid layers will move down with the soil movement underneath the footing. For longer layers, sufficient anchorage length mobilizes larger lateral resistance than that built up underneath the footing and therefore with footing settlement the geogrid will not move down with supporting soil but mobilize greater resistance up to maximum pullout capacity of geogrid layer after which the system fails.

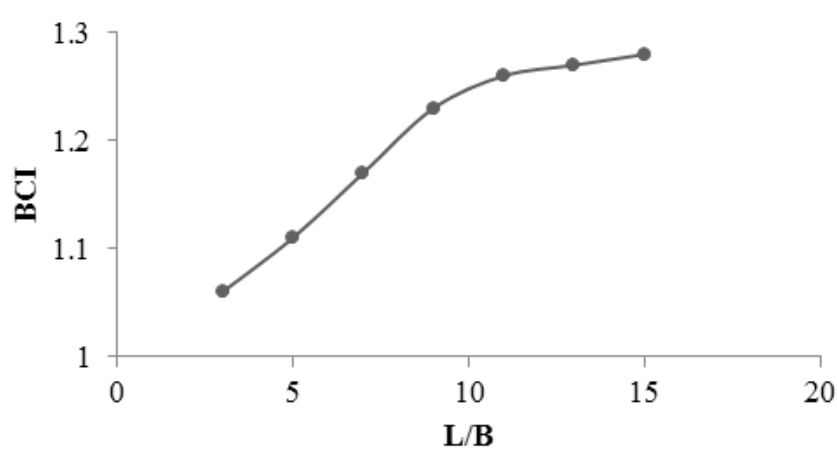

Fig. 4. Variations of $B C I$ with geogrid layer length $L / B$.

\subsubsection{Effect of Footing Location Relative to Slope Crest}

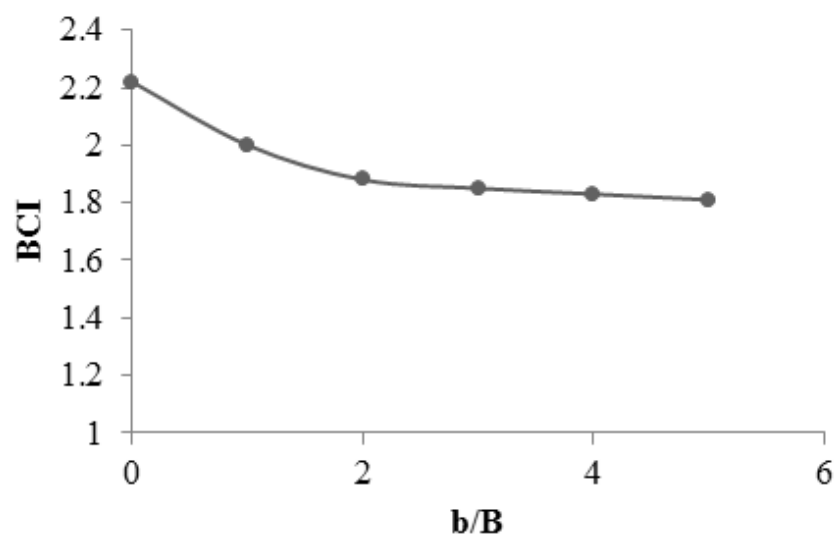

Fig. 5. Variations of BCI with footing location $b / B$.

In order to study the effect of the proximity of a footing to the slope crest $(\mathrm{b} / \mathrm{B})$, a series of tests were carried out on industrial machinery foundation resting on reinforced sand fill overlying soft clay slopes. While the first was carried out on non-reinforced sand fill, the second was carried out on 3layer of geogrid- reinforced sand. Fig.5.shows the variation of the BCI against the $\mathrm{b} / \mathrm{B}$ ratios for model results. It can be seen that, while the bearing capacity load significantly decrease as the footing location moves closer to the slope crest, the effect of soil reinforcement on the bearing capacity significantly increase. Also, the figure clearly shows that maximum benefit of slope geogrid reinforcement is obtained when footing is placed at slope crest. This change in bearing capacity of the footing with its location relative to slope crest can be attributed to soil passive resistance from the slope side and reinforcement effect. When, the footing is placed far away of the slope, the passive resistance from the slope side to the failure wedge under the footing increases. Also, using geogrid reinforcement decreases lateral displacements and results in wider and deeper failure zone as discusses in previous sections, leading to increasing the bearing capacity load.

\subsection{Effect of Depth to Top Layer}

The effect of depth of the geogrid layer to the ground surface $\mathrm{x} / \mathrm{B}$ is studied using only one layer of geogrid placed in dense sand at different depths of ground surface. Seven tests were carried out on model footing using FEA. Fig.6 shows the variation of the BCI of the footing against the normalized depth $\mathrm{x} / \mathrm{B}$ for model footing. Graph clearly show that the BCI initially increases with increasing the depth until it attains a maximum value after which the BCI comes down with increasing the depth of geogrid layer. Also, the variation of BCI with $\mathrm{x} / \mathrm{B}$ reported by Selvadurai and Gnanendran (1989) and Yoo (2001) for reinforced sand slope are similar to that obtained from the present investigation. This can be explained as follows; at shallow depths under the footing, both the vertical and horizontal soil displacements are greater. Maximum benefits could be obtained when soil reinforcement are placed at these depths where mobilized lateral resistances for soil lateral displacements are maximum. When the depth of geogrid layer increases, both lateral and vertical soil displacements in the zone between the footing and the geogrid layer increase and hence the bearing capacity decreases.

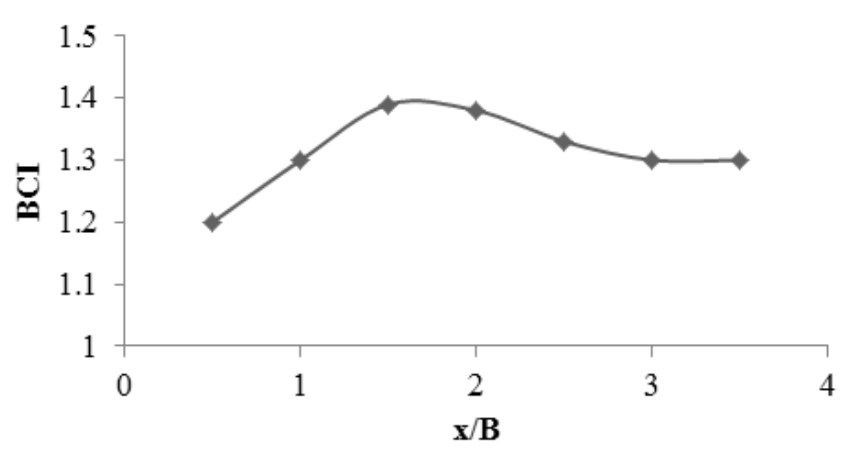

Fig. 6. Variations of BCI with depth of geogrid layer $x / B$.

\subsection{Effect of Pre stressed GeoGrid}

To assess the effect of presence pre stressed geogrid layers, initially three types of embankments are modeled: in first step consider an embankment without geogrid, in second step three layers of geogrid are introduced between the embankment and the under laying soft soil and for last step of analyses, three layers of pre stressed geogrid are considered and they are placed between the embankment to investigate the degree of improvement generated by pre stressing the geosynthetic layer for several embedment depths of a footing resting on a reinforced sand bed. The addition of pre stress to the geogrid reinforcement results in significant improvement to the settlement response and the load-bearing capacity of the foundation. Fig.7 the beneficial effects of the pre stressed geogrid configuration were evident, in comparison with unreinforced and reinforced (without pre stress) counterparts. 


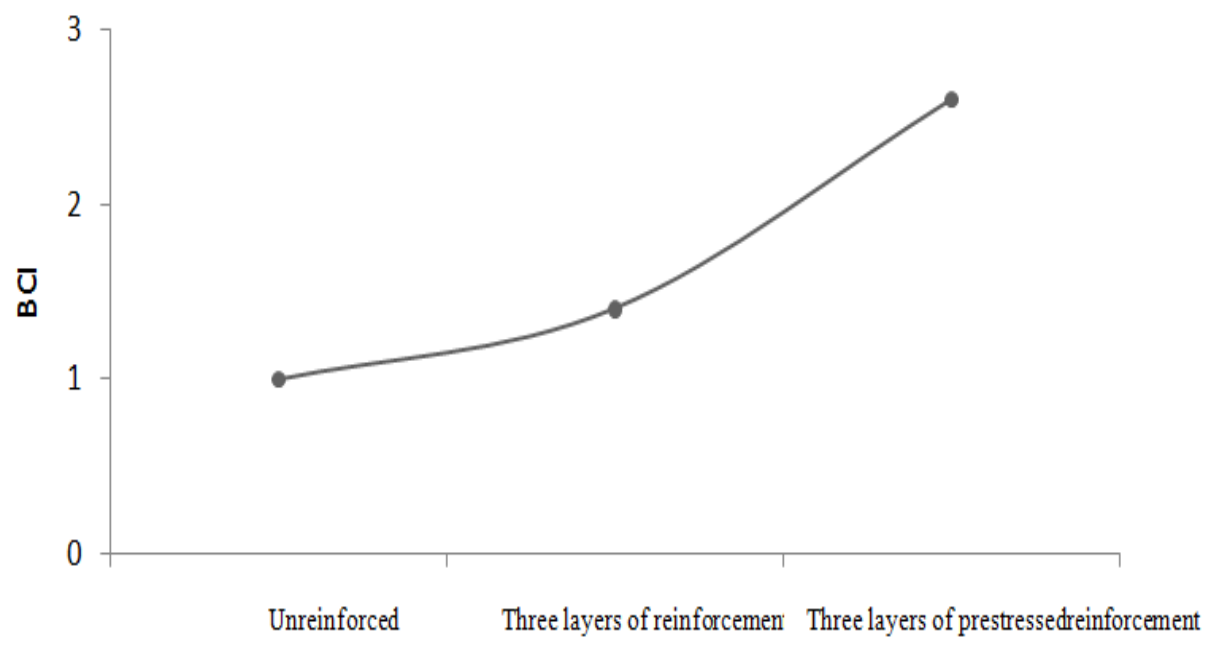

Fig. 7. Variations of BCI with number of geogrid layer $N$.

\section{Displacement Vectors}

Fig.8.and Fig.9 presents the failure pattern and deformed mesh for a footing placed at the crest of both the nonreinforced and three-pre stressed geogrid layers reinforced slope, respectively. The figure clearly shows the tendency of the footing rotation toward the slope face on reinforced test while in tests on non-reinforced slope, the footing tend to fail by punching shear failure. Typical plots of the displacement vectors obtained from the FEA are also presented. Comparing the plastic flow between these two cases, it can be observed that displacement vectors at failure for nonreinforced slope are concentrated underneath the footing toward the slope face while for the reinforced slope, the displacement vectors are widely distributed underneath the footing for greater width and depth than that in the nonreinforced case. It is clear that the geogrid layers prevent the soil particles from lateral movement toward the slope face and pushes them downward for greater depth and hence spreads the footing load wider and deeper into the soil, which in turn meant a longer failure surface and greater bearing capacity.

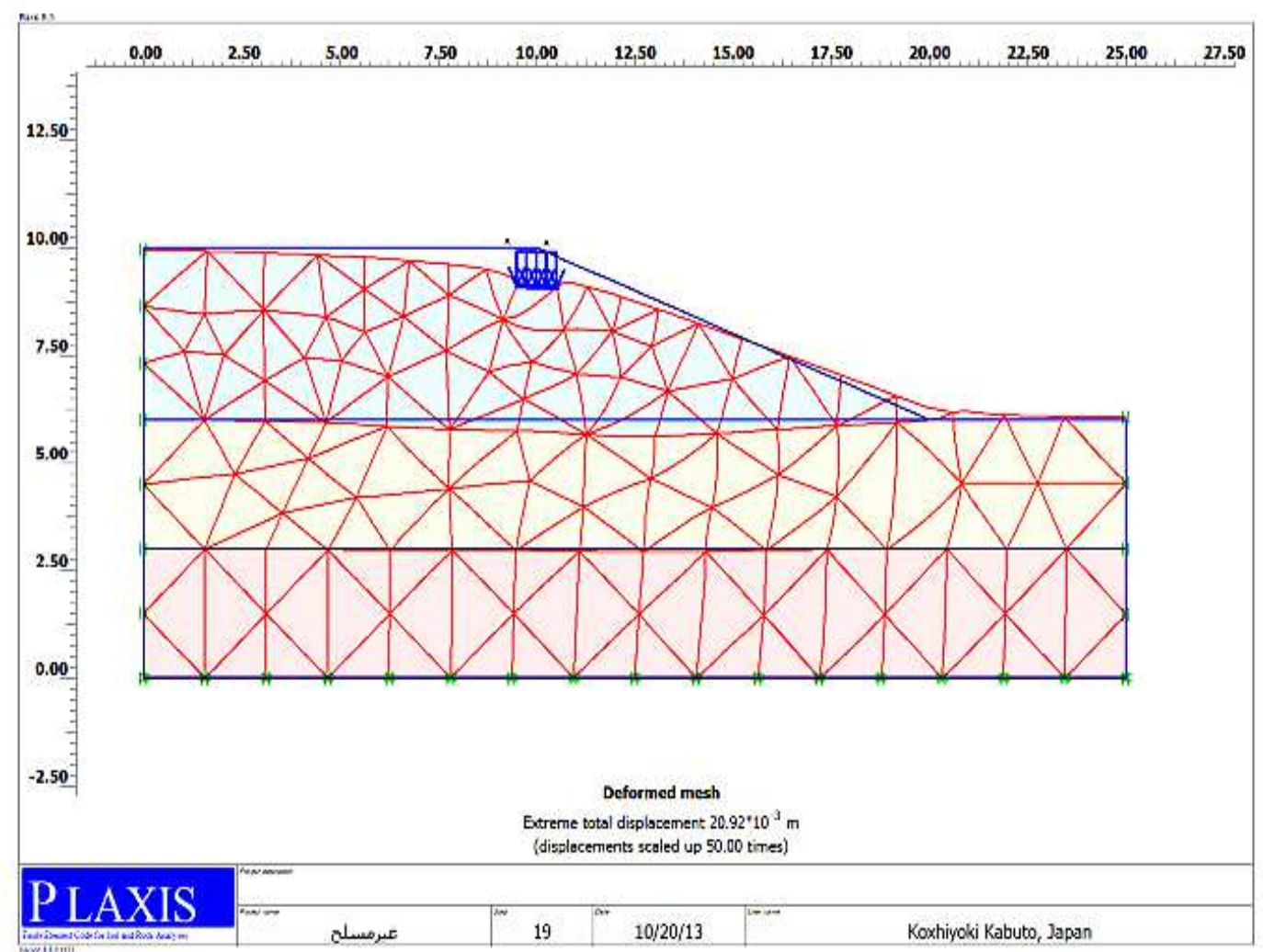




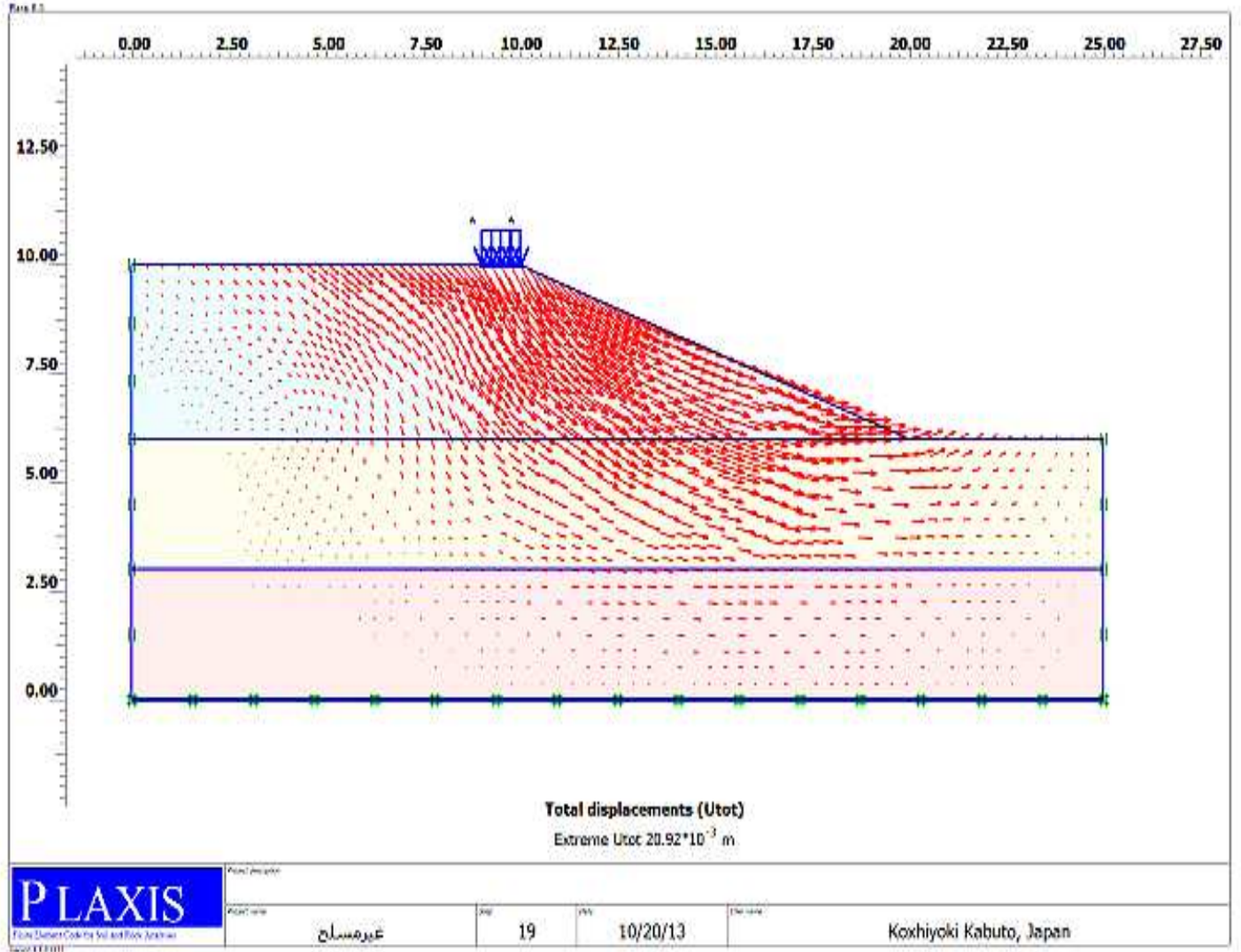

Fig. 8. Failure pattern and displacement vectors plot for non-reinforced slope.

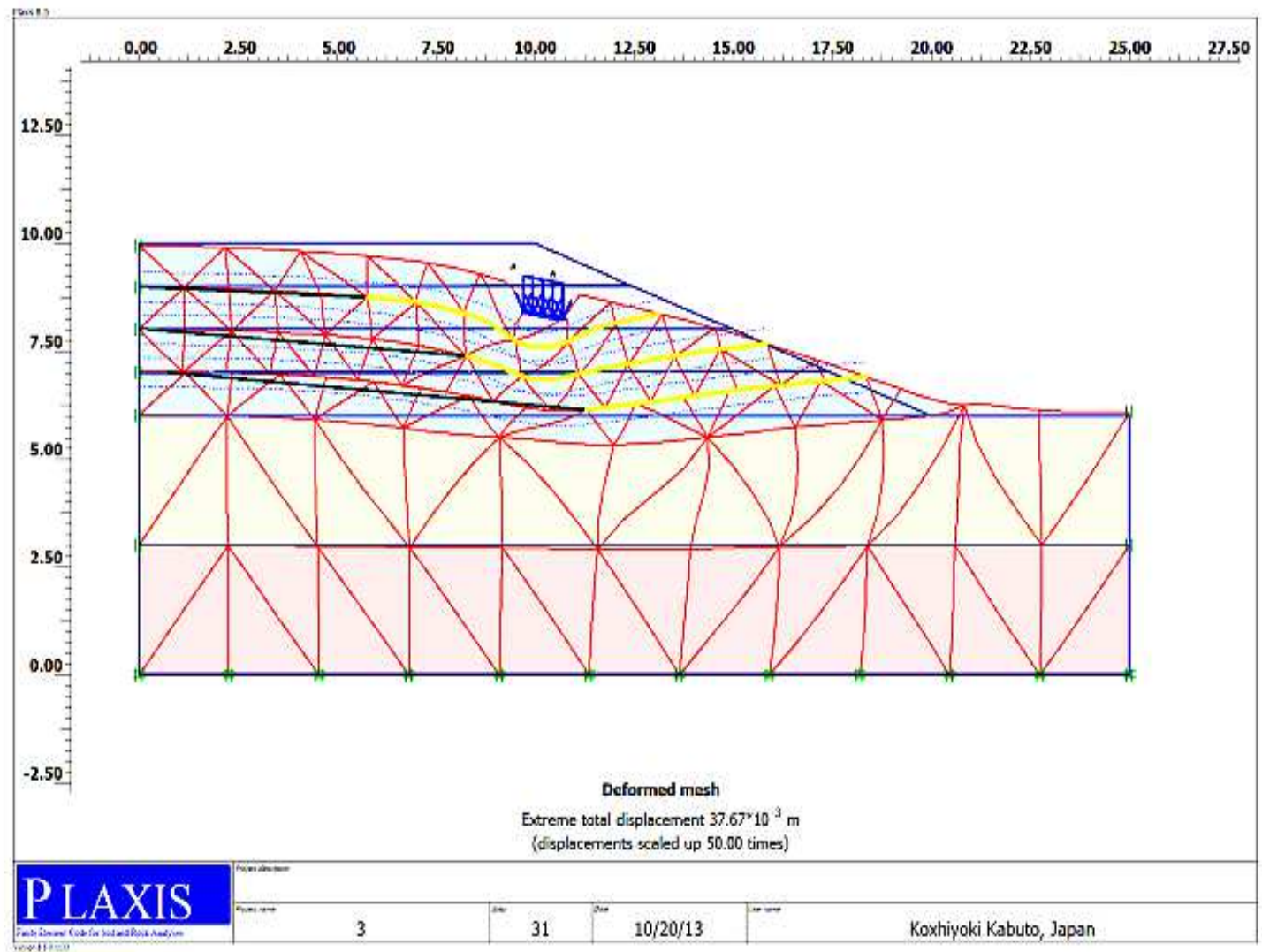




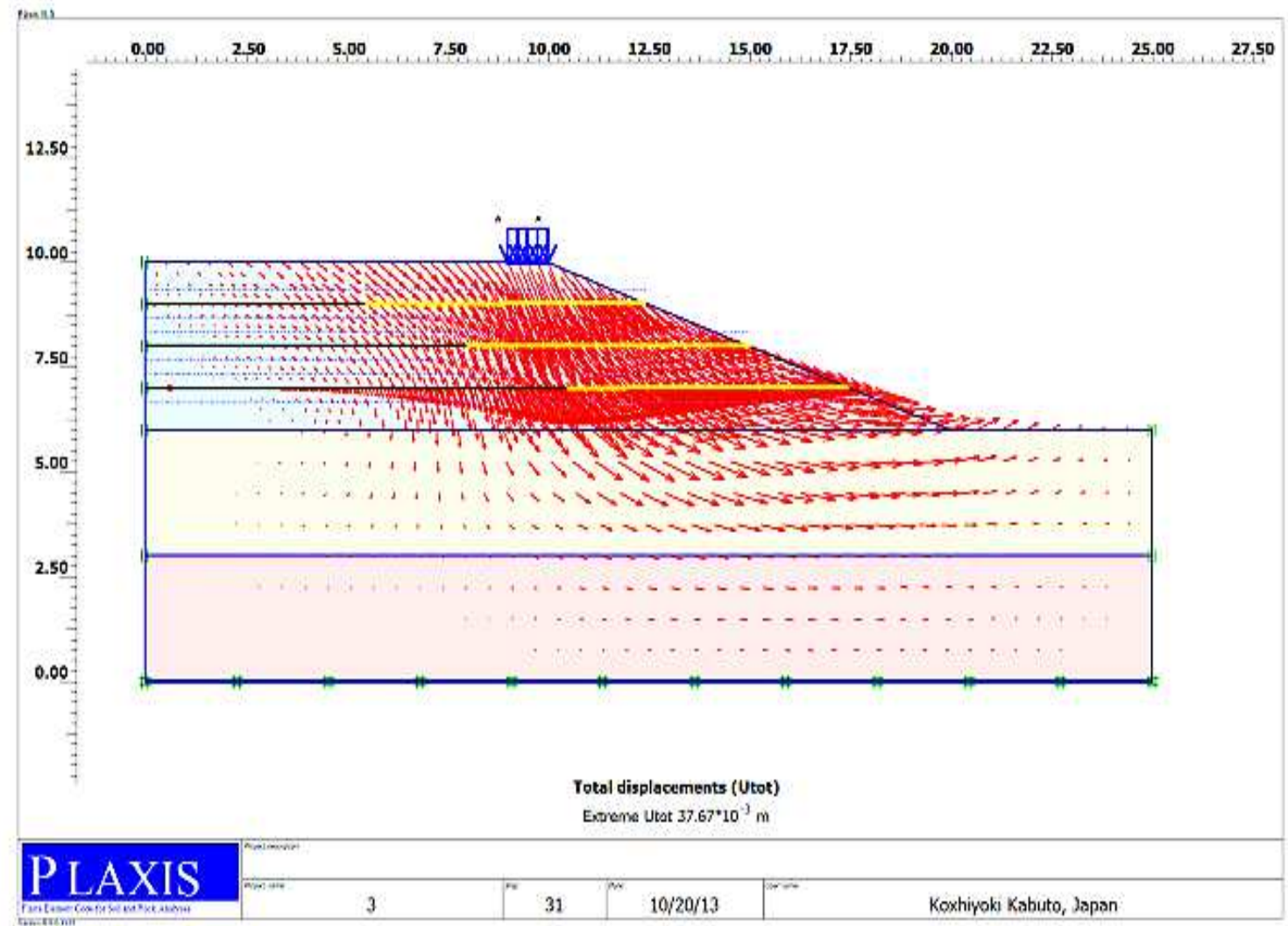

Fig. 9. Failure pattern and displacement vectors plot for reinforced slope.

\section{Conclusions}

The bearing capacity behavior of industrial machinery foundation resting on reinforcement sand layer constructed on a soft clay slope was investigated. Also, the effect of inclusion of pre stressed geogrid reinforcement on the footing response was studied theoretically. Wide ranges of boundary conditions including footing location and the geogrid parameters were considered. Based on the results from this investigation, the following conclusions can be drawn:

(1)The inclusion of soil reinforcement not only improves the footing behavior but also leads to significant reduction of footing settlement, at the same load levels.

(2)The effect of geogrid reinforcements on the footing performance is dependent on the footing location relative to slope crest. In terms of BCI, geogrid is most effective when the footing is placed on the slope crest rather than any distance away from the slope crest.

(3) For a footing located at slope crest, an adequate anchorage length for each geogrid layer should be provided along with an optimum number of geogrid layers should be used.

(4) For the studied slope geometry and conditions, the maximum benefit of geogrid reinforcements is dependent on reinforcement configuration. The BCI initially increases with increasing the depth until it attains a maximum value after which the BCI comes down with increasing the depth of geogrid layer.

(5)Using three pre stressed layers of geotextile between the embankment base and the under laying soft layer decrease vertical and horizontal displacement and increase BCI and the beneficial effects of the pre stressed geogrid configuration were evident, in comparison with unreinforced and reinforced (without pre stress) counterparts

\section{References}

[1] Bringkgreve, R., Vermeer, P., 1998. PLAXIS-Finite Element Code for Soil and Rock Analysis. Version 7 Plaxis B.V., the Netherlands.

[2] British Rail Research, 1998. Supporting roll—geogrids provide a solution to railway track ballast problems on soft and variable subgrades. Ground Engineering 31 (3), 24-27.

[3] Das, B., Khing, K., Shin, E., Puri, V., Yen, S., 1994. Comparison of bearing capacity of strip foundation on geogrid-reinforced sand and clay. In: Proceedings of the Eighth International Conference on Computer Methods and Advances in Geomechanics, Morgantown, WA, USA, pp. 1331-1336.

[4] Dash, S., Sireesh, S., Sitharam, T., 2003. Model studies on circular footing supported on geocell reinforced sand underlain by soft clay. Geotextiles and Geomembranes 21 (4), 197-219.

[5] El Sawwaf, M., 2005. Strip footing behavior on pile and sheet pilestabilized sand slope. Journal of Geotechnology and Geoenvironmental Engineering 131 (6), 705-715. 
[6] Ghosh, A., Ghosh, A., Bera, A.K., 2005. Bearing capacity of square footing on pond ash reinforced with jute-geotextile. Geotextiles and Geomembranes 23 (2), 144-173.

[7] Boushehrian, J.H., Hataf, N., 2003. 241 Experimental and numerical investigation of the bearing capacity of model circular and ring footings on reinforced sand. Geotextiles and Geomembranes 21 (4), 241-256.

[8] Otani, J., Ochiai, H., Yamamoto, K., 1998. Bearing capacity analysis of reinforced foundations on cohesive soil. Geotextile and Geomembranes 16, 195-206.

[9] Patra, C.R., Das, B.M., Bhoi, M., Shin, E.C., 2006. Eccentrically loaded strip foundation on geogrid-reinforced sand. Geotextiles and Geomembranes 24 (4), 254-259.

[10] Tsukada, Y., Isoda, T., Yamanouchi, T., 1993. Geogrid subgrade reinforcement and deep foundation. In: Raymond, Giroud (Eds.), Proceedings of the Geosynthetics Case Histories. ISSMFE, Committee TC9, pp. 158-159.

[11] Vesic, A., 1973. Analysis of ultimate loads of shallow foundations. Journal of Soil Mechanics and Foundations Division-ASCE 94 (SM3), 661-688.

[12] Yetimoglu, T., Inanir, M., Inanir, O., 2005. A study on bearing capacity of randomly distributed fiber-reinforced sand fills overlying soft clay. Geotextiles and Geomembranes 23 (2), 174-183.

[13] Huang, C.C., Menq, F.Y., 1997. Deep footing and wide-slap effects on reinforced sandy ground. Journal of Geotechnical and Geoenvironmental Engineering, ASCE 123 (1), 30-36.

[14] Ismail, I., Raymond, G.P., 1995. Geosynthetic reinforcement of granular layered soil. In: Proceedings of Geosynthetics '95 Conference, Nashville, TN, vol. 1. Industrial Fabrics Association International, Roseville, MN, USA, pp. 317-330.
[15] Khing, K.H., Das, B.M., Puri, V.K., Cook, E.E., Yen, S.C., 1993. The bearing capacity of a strip foundation on geogridreinforced sand. Geotextiles and Geomembranes 12 (4), 351361.

[16] Koerner, R.M., 2005. Designing with Geosynthetics, fifth ed. Prentice Hall, New Jersey, USA. Kurian, N., Beena, K.S., Kumar, R.K., 1997. Settlement of reinforced sand in foundations. Journal of Geotechnical Engineering 123 (9), 818-827.

[17] Madhav, M.R., Poorooshasb, H.B., 1988. A new model for geosynthetic-reinforced soil. Computers and Geotechnics 6, 277-290.

[18] Meyerhof, G.G., 1963. Some recent research on bearing capacity of foundations. Canadian Geotechnical Journal 1 (1), $16-26$.

[19] Shukla, S.K., 2002. Geosynthetics and their Applications. Thomas Telford, London. Shukla, S.K., Yin, J.H., 2006. Fundamentals of Geosynthetic Engineering. Taylor and Francis, London.

[20] Shukla, S.K., 1995. Foundation model for reinforced granular fill - soft soil system and its settlement response. Ph.D. thesis, Department of Civil Engineering, Indian Institute of Technology, Kanpur, India.

[21] Alawaji, H., 2001. Settlement and bearing capacity of geogrid-reinforced sand over collapsible soil. Geotextiles and Geomembranes 19, 75-88.

[22] Bera, A.K., Ghosh, A., Ghosh, A., 2005. Regression model for bearing capacity of a square footing on reinforced pond ash. Geotextiles and Geomembranes 23 (2), 261-286.

[23] Ovesen, N.K., 1979. The use of physical models in design: the scaling law relationship. In: Proceedings of the Seventh European Conference on Soil Mechanics and Foundation Engineering, vol. 4, pp. 318-323. 